\title{
Composite Bridges with Integral Abutments Minimizing Lifetime Cost
}

\section{Hans Pètursson}

Lic. In Engineering Steel Structures SICOMP

Luleå, Sweden

Hans Pètursson, born 1966, received his Licentiate in Engineering degree from the Lulea Univ. of Technology 2000. He has since been working with design and development of FRP structures .

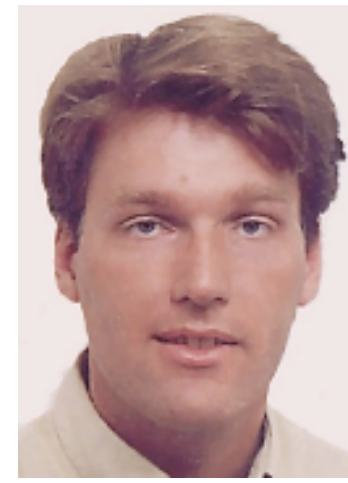

\section{Summary}

\section{Peter Collin}

Prof Composite Structures LTU/Scandiaconsult

Luleå, Sweden

Peter Collin, born 1960, presented his PhD thesis 1992, concerning the stability of steel frames. He has since been working with design and development of steel- and composite bridges.

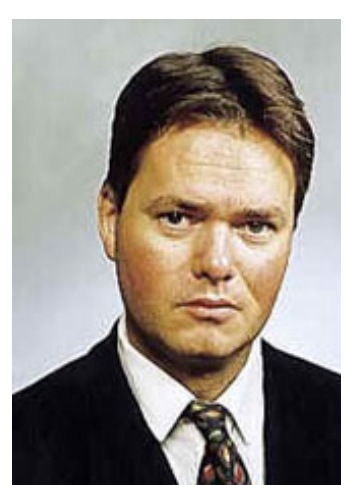

The cost of maintenance is an ever-growing problem for road administrations around the world, and bridges are no exception to the rule. One way to reduce the need for future maintenance, as well as the investment cost, is to make bridges without transition joints. In order to investigate if the crossshaped steel pile commonly used in Sweden is suitable for use in integral abutments, two full-scale laboratory tests were carried out. Experience from the United States shows that bridges with integral abutments are increasingly outclassing the traditional bridges with joints, the former being not only less expensive to maintain, but also more affordable to build. In the following, two analytical methods are described that can be used to calculate the capacity of piles based on plastic design.

Keywords : integral abutments, steel piles, composite bridges.

\section{1) Introduction}

In some parts of USA, bridges with integral abutments have been built since the 1960's.

In Iowa bridges with integral abutments have been showing satisfying performance since 1964 [1]. The longest bridge measures approximately $100 \mathrm{~m}$.

Featuring more than 2,400 bridges with integral abutments, Tennessee is probably the state with the widest experience of this type of bridge [2]. Over the years, the Department of Transportation has gradually extended the limits for the length of bridges with integral abutments to the current maximal $120 \mathrm{~m}$ for steel bridges and $240 \mathrm{~m}$ for concrete bridges. The limits are based on the expected movement at the bridge ends, which shall be less than $100 \mathrm{~mm}$ (50 mm at each end). The longest concrete bridge with integral abutments is $352 \mathrm{~m}$ and the longest in steel is $152 \mathrm{~m}$.

Each year, New York State spends $\$ 7$ million on replacements and repair of bridge joints 0. In the beginning of the 1980's, the first integral abutment bridge was built. By 1996, 155 bridges with integral abutments had been built in the state. When a bridge is built today, the New York State Department of Transportation always tries to eliminate joints whenever possible.

In order to understand the mechanisms of an integral abutment, it is necessary to study the effect that movement in the abutment has on the stresses in the pile. The bridge length varies with the structure's temperature. Movements in the piles are also induced by rotations of the superstructure.

Analysing the load carrying capacity of piles subjected to lateral movements is complex as it contains two co-dependent elements; the flexural pile and the soil. To further complicate matters, soils are not always homogeneous. Analytical solutions are only possible to obtain for simple cases where the stiffness of the soil is constant along the pile and the materials feature elastic behaviour. Expressions for the case with constant soil stiffness are given by theories for beam on an elastic foundation [3]. To handle more complex cases where soil stiffness varies with depth, an equivalent stiffness can be assumed.

Although a section in a steel pile may reach yield stresses, this does not imply that the ultimate load is reached. The moment along the pile can be re-distributed and further load increase is possible. If elastic theory is used to calculate the moment distribution along the pile, the re-distribution effect is not 
accounted for. Analytical methods have been developed to calculate the capacity of piles based on plastic design.

\section{2) Testing of steel piles restrained by elastic springs}

The purpose of the tests described in this section was to detect the decrease of load carrying capacity of an elastically restrained steel pile, when the pile top is subjected to deflections arising from the traffic load. The piles tested were X130×16 mm, delivered from Fundia AB.

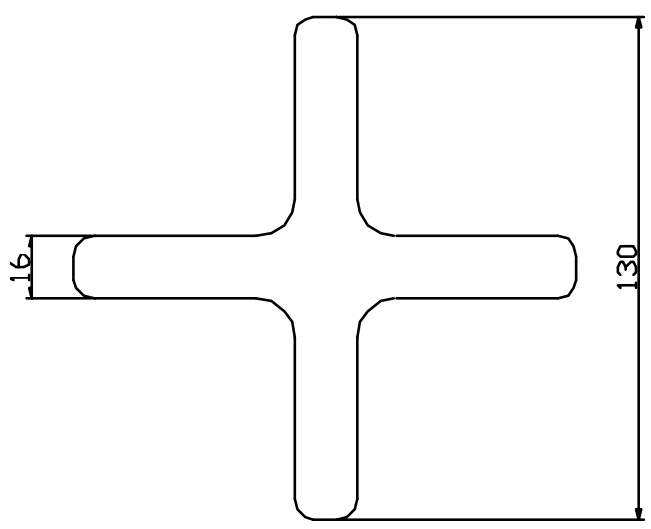

Fig. 1 Cross section of the X130 pile.

One end of the pile was embedded in a concrete block to $500 \mathrm{~mm}$. The concrete block was supposed to mimic the back wall of a bridge. The dimensions of the concrete block were $? ? 0 \times 0 . ? ? \times 0.75 \mathrm{~m}$.. Springs were attached to the pile at $1 \mathrm{~m}$ spacing. The springs would then respond to any pile movement in a manner resembling that of the soil around a bridge pile. After moving the concrete block $25 \mathrm{~mm}$ transversely relative the pile, the latter was subsequently loaded through the concrete block until failure.

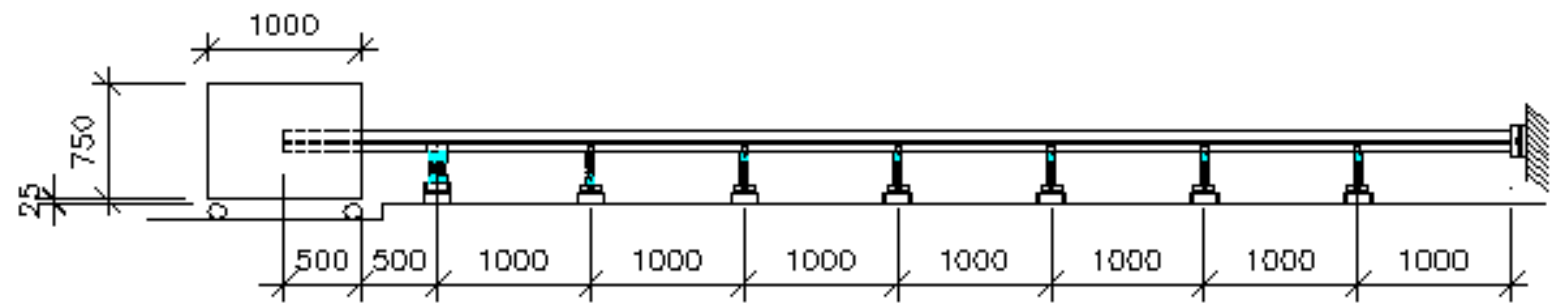

Fig. 2 The test set-up.

The result shows that the load carrying capacity was substantial even after the transverse deformation.

The configuration of the testing can be seen in

Fig. 2. The pile top was deflected $25 \mathrm{~mm}$ perpendicular to the pile length axis.

The yield stress of the steel in the piles was $310 \mathrm{MPa}$ according to the manufacturer and it was proven by tensile tests of the steel (see Table 1).

Table 1 Results from tensile tests of steel in piles.

\begin{tabular}{cccc}
\hline & $\boldsymbol{f}_{\boldsymbol{y}}(\boldsymbol{M P a})$ & $\boldsymbol{f}_{\boldsymbol{u}}(\boldsymbol{M P a})$ & $\boldsymbol{E}(\boldsymbol{G P a})$ \\
\hline Test pile 1 coupon 1 & 325 & 513 & 225 \\
Test pile 1 coupon 2 & 321 & 509 & 218 \\
Test pile 2 coupon 1 & 320 & 504 & 197 \\
Test pile 2 coupon 2 & 317 & 506 & 215 \\
\hline
\end{tabular}


The results of the tests showed that the piles capacity was $73 \%$ and $79 \%$ of the theoretical capacity of a perfectly straight pile. The pile tests were also simulated with the FE-program DIANA. The results from the FE-simulations showed good agreement with the pile tests (within 5\%). This made it possible to simulate the ultimate load for a variety of conditions to verify the proposed design method. The FE-analysis is described in more detail in [4].

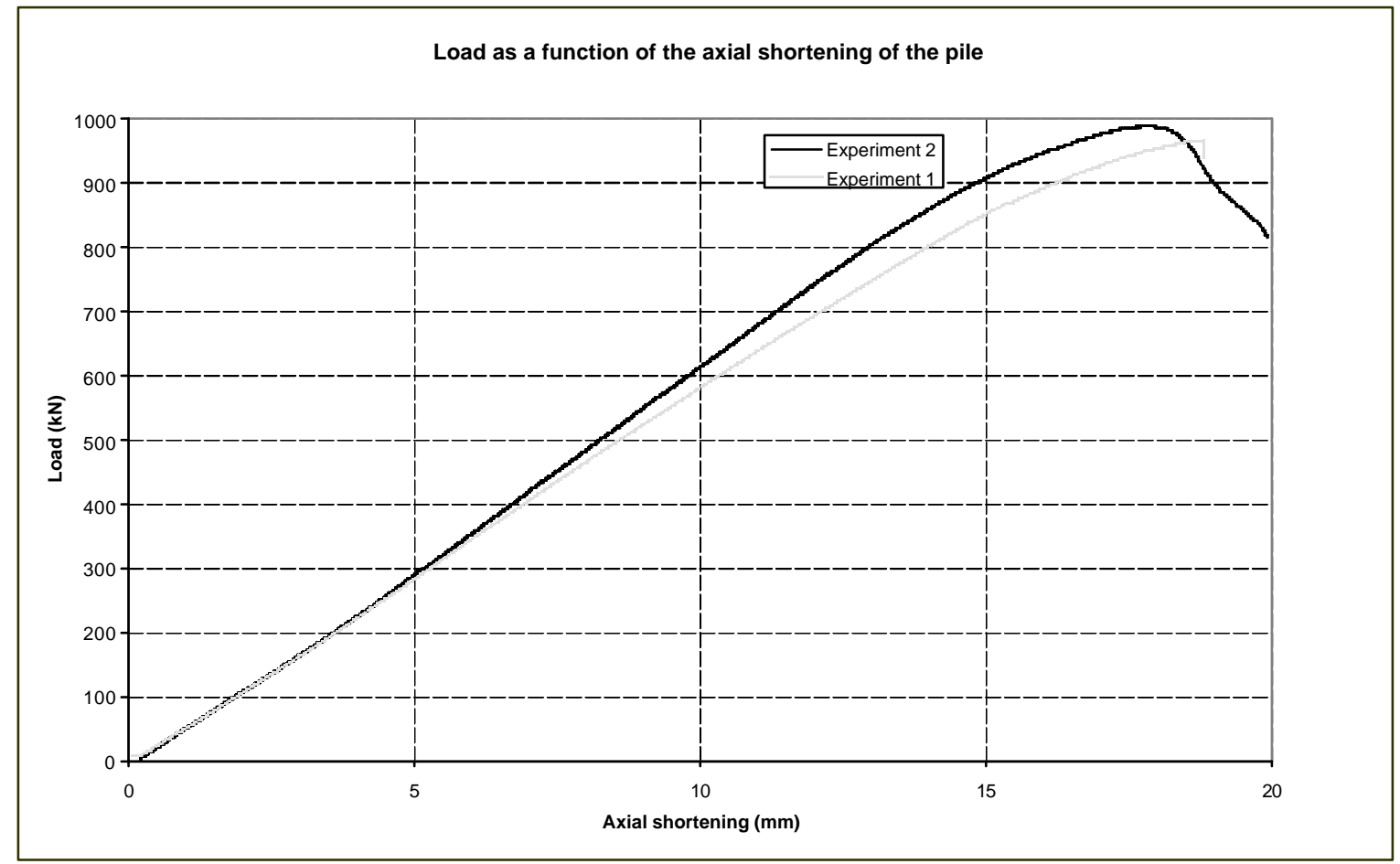

Fig. 3 Results from pile testing.

Table 2 Results from pile testing.

\begin{tabular}{lccc}
\hline & $\begin{array}{c}\text { Ultimate load } \\
\text { test }(\mathrm{kN})\end{array}$ & $\frac{\text { Ultimate load }}{\left(\mathrm{f}_{\mathrm{yk}} \times \mathrm{A}\right)}$ & $\begin{array}{c}\text { Ultimate load } \\
\mathrm{FE}(\mathrm{kN})\end{array}$ \\
\hline Test 1 & 967 & 0,73 & 1005 \\
Test 2 & 990 & 0,79 & 1007 \\
\hline
\end{tabular}

\section{3) Pilot Project -Bridge over Fjällån}

In the 1980's a few bridges with integral abutments were built in Sweden. Most of the short to medium span bridges in Sweden are semi-integral, meaning that there are no joints on the road surface but that the bridge rests on bearings. In a project at Lulea University of Technology it was investigated if the cross-shaped piles were suitable for integral bridges. Within the project a bridge was built in the Swedish province of Västerbotten, completed in September 2000. The bridge was a single span composite bridge with a span length of $37.15 \mathrm{~m}$. 
Fig. 4 Bridge over Fjällån after completion

In order to minimise the bending stresses arising from the deflection of the bridge, the work was carried out in the following way:

1) Eight piles, $X 180 \times 24 \mathrm{~mm}$, were used for each abutment. The piles were rotated 45 degrees from the line of support, minimising the bending stresses from the traffic load, (see Fig. 5.)

2) The side wings and the lower parts of back walls were cast.

3) The steel girders were erected on steel bearings on top of the lower part of the back wall as seen in. On safe-hand side, the girders were designed as simply supported girders, not taking the restraint from the embankment into account.

4) The formwork for the side wings was removed, giving the steel piles a rotation in the opposite direction of the one arising from the traffic. In other words, the piles were pre-stressed.

5) The upper parts of the back walls were cast together with the concrete deck of the bridge.

6) The embankment behind the back walls was filled up, and the pavement as well as the side rails was placed on the bridge.

One of the main reasons why integral abutment bridges have not yet become common in Sweden is the difficulty to analyse them.

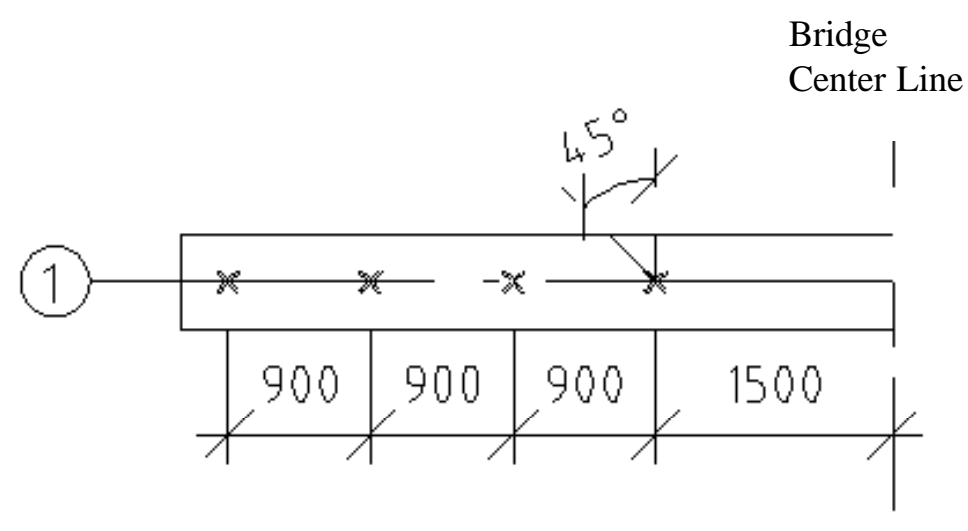

Fig. 5 Pile configuration. 


\section{4) Design Method Proposal}

\subsection{Global analysis}

The global analysis can be carried out in a number of ways. To be competitive, bridges with integral abutments need to be designed in a rational manner. With computer programs it is possible to model the interaction between piles and bridge deck in a realistic manner. The ultimate strength of the piles can be calculated with FEM where the non-linear behaviour of the steel piles and earth surrounding the piles are modelled in a realistic way. Stresses in serviceability state for piles in soils where properties vary with depth are also convenient to calculate with FEM. Non-linear FEcalculations are often time consuming and not wide spread among bridge engineers. And even if designers have the necessary tools to make an advanced un-linear FE-analysis there is a need for a simpler method

The global analysis is often made with a 2D computer program with beam elements. This can also be done for a bridge with integral abutments. The connection between the back-wall and the piles can be regarded as pinned and the girder can be assumed to expand and extract without resistance. The stiffness of the piles is low and can be neglected compared to the stiffness of the girder. To include the normal force and moment of the earth pressure against the back wall spring elements can be used. The springs should have different properties in tension and compression to account for passive and active earth pressure.

\subsection{Serviceability Limit State}

Usually the calculated stress in a steel component shall not exceed characteristic value of the yield stress in the serviceability limit state. In reality residual stresses from manufacturing are added to the calculated stresses. Welded beams have residual stresses around the welds that can be as high as the yield stress even before the beams are loaded. One argument for having the yield strength as a limit in serviceability limit state is to prevent plastic deformation from accumulating and thus giving a bent impression of the structure. In an integral abutment accumulated plastic deformation in the piles will not affect the bridge deck due to the difference in stiffness.

Another argument is that the accumulated deformations also accelerate the strains and finally cause a collapse. The loads that can cause repeated yielding in the piles are traffic and temperature. The moments that are induced by these loads are interacting when the temperature is high.

Assume that a pile is subjected to a great number of load cycles with stochastic varying magnitude. In the worst case the stress in the pile reaches yield stress in compression in one edge and is then unloaded elastically. If the magnitude of the next load cycle is exactly the same the stress will reach the yield stress but no additional plastic deformations will occur. The stress will not reach the yield stress if the magnitude of the load is less in the second cycle than the first.

In reality the weight of the trucks that passes over a bridge will vary and there will not be two identical load cycles. As the number of trucks increases the risk of additional plastic deformation decreases. Thus the number of cycles that cause plastic deformation will be limited.

If the load amplitude of the cycles are varying in a stochastic manner the chance of all time high stress in the pile is:

For load cycle 1: $100 \%$

For load cycle 2: $50 \%$

For load cycle 3: 33\%

etc.

The total number of cycles that causes all time high stress in the pile can be written as the sum of $1 / \mathrm{x}$ were $\mathrm{x}$ goes from 1 to total number of load cycle. Integration gives a value that for 400000 load cycles gives

$$
\stackrel{?}{400,000} \frac{1}{n} d n ? \ln (400,000) ? \ln (0.5) ? 14 \text { load cycles }
$$


This does not mean that all 14 cycles will give plastic deformation.

The traffic loads in most design codes are of a magnitude that most trucks do not reach. The worst case when the temperature in the structure reaches the design value only occurs for a limited numbers of days every year. The conclusion is that plastic deformations will only occur a few times even if the calculated stresses will exceed the yield stress

If yield stresses shall be allowed in steel piles the restriction is that low cycle fatigue should be avoided. This can be done with Whöler diagrams. The strain width that is calculated in the piles is substituted by stress width. The stress width is calculated as strain times $E=210 \mathrm{GPa}$. The number of cycles that can be permitted with the strain width ? can be written as:

$$
n_{t}=\stackrel{?}{?} \frac{C}{E ? ? ? 1.1 ? 1.2} \stackrel{?}{?} ?
$$

$\mathrm{C}=$ detail category according to Euro code 3,112 MPa.

$\mathrm{E}=$ elastic Young's modulus

$?=$ strain width

If the yield strength in the pile is $355 \mathrm{MPa}$ and the strain width in the serviceability is $6355 / 210000=1,0 \%$ the number of cycles before fatigue limit is reached:

$$
n_{t} ? \stackrel{?}{?} \frac{112}{6 ? 355 ? 1.11 .2} \stackrel{?}{?} ?
$$

If it is assumed that the design values for traffic and temperature are reached once every year each in a stochastic manner the probability that they occur simultaneously is one in 133000 . It is highly unlikely that temperature and traffic load will occur at the same time during the 100 years that a bridge is supposed to be in service, if the assumptions above are true There are however loads of a smaller magnitude that will cause fatigue damage to the pile.

There are a number of parameters that influence the magnitude of the strains in a pile, such as temperature variation, numbers of trucks that pass the bridge and their weight, span length, stiffness of soil surrounding the pile, stiffness of the bridge deck and the height of the abutment wall. It is thus difficult to suggest design rules that are valid for all bridges with integral abutments. An attempt to quantify the strains than can be expected in a bridge with integral abutments is described in [4].

The moment that acts on a pile due to temperature change in the bridge deck is:

$$
M_{0} ? \frac{? ? k_{h} ? L^{2}}{2} ? \frac{? ? k_{h} ? \sqrt{\frac{4 ? E ? I}{k_{h}}}}{2} ? ? ? \sqrt{k_{h} ? E ? I}
$$

If the stress reaches yield the moment can be expressed as:

$$
M_{0} ? \frac{2 ? f_{y} ? I}{b}
$$

If the two expressions above are equal then the soil stiffness is: 


$$
k_{h} ? \frac{4 ? f_{y}^{2} ? I}{?^{2} b^{2} ? E}
$$

The strains caused by traffic depend on a number of parameters. If both the steel pile and soil are elastic the strain is:

$$
? ? \frac{N}{A ? E} ? \frac{b}{I ? E} ? \frac{? ? k_{h} ? L^{2} ? ? ? k_{h} ? L^{3}}{4}
$$

If the traffic load is added when the pile top have obtained yield stress the strains will be higher. The rotation is assumed to take place in a region of the pile that has a length twice the size of the width of the pile and the plastic region acts like a frictionless hinge where the strain will be:

$$
? ? ?_{N} ? \frac{?}{2 ? L} ? \frac{?}{2} ? ?_{N} ? \frac{?}{2 ? \sqrt[4]{\frac{4 ? E ? I}{k_{h}}}} ? \frac{?}{2}
$$

It is reasonable to design the pile as a pile with hinged connection at the top in the serviceability stage. This way the stresses in the pile will be limited and a plastic hinge is allowed to form in the pile top. The design can then be done with conventional methods. An analysis can have the following steps:

1) The global analysis gives the axial force $\mathrm{N}$, horizontal displacement ? $\mathrm{D}$ and rotation ? ?with appropriate?partial load factors ?. The horizontal displacement at the piles:

? ? ${ }_{\circ} ? ? ? e$

where e is the vertical distance from the centre of the bridge deck to the pile top. The horizontal displacement? should not exceed $25 \mathrm{~mm}$ in the serviceability limit state.

2) The stress in the pile is calculated as:

$? ? \frac{N}{A} ? \frac{b}{I} ? \frac{? k_{h} ? L^{2}}{4}$

and shall not exceed $\mathrm{f}_{\mathrm{yk}}$.

\subsection{Ultimate limit state}

The capacity in the ultimate limit state is limited by buckling and by moment/rotational capacity as illustrated in Fig. 6. The load capacity in the ultimate limit state is according to Granholm [5]. 


$$
\frac{N_{u}}{N_{c r}} ? \frac{N_{u}}{N_{p}} ? 1.00
$$

$\mathrm{N}_{\mathrm{p}}=$ plastic capacity (see Fig. $6 \mathrm{~b}$ )

$\mathrm{N}_{\text {cr }}=$ elastic buckling load (see Fig. 6a.)
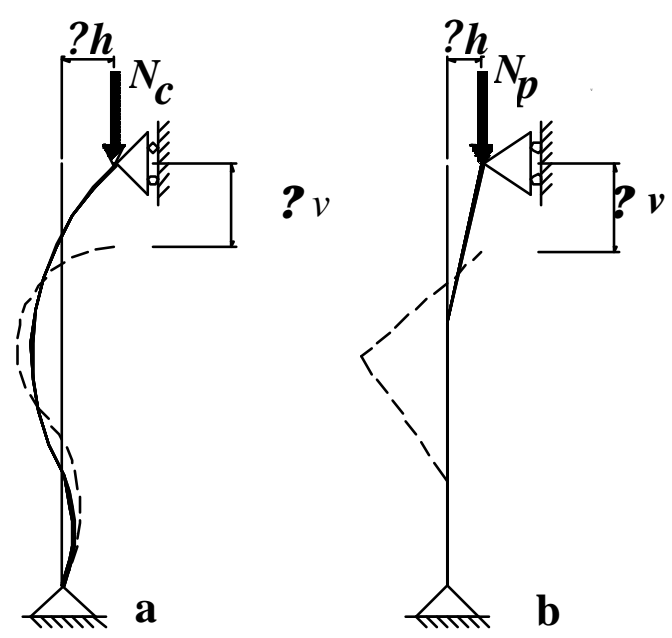

Fig. 6 Pile capacity is limited by buckling and moment capacity.

To calculate the buckling load the following equation can be used for pile with hinged top and where the stiffness of the soil is constant [6]:

$$
\mathrm{N}_{\mathrm{cr}} ? 2.0 ? \sqrt{\mathrm{k}_{\mathrm{h}} ? \mathrm{E} ? \mathrm{I}}
$$

If the pile top is fixed the buckling load is [6]:

$$
\mathrm{N}_{\text {cr }} ? 2.5 ? \sqrt{\mathrm{k}_{\mathrm{h}} ? \mathrm{E} ? \mathrm{I}}
$$

For soils with linearly varying stiffness with depth and pinned top the buckling load is [6]:

$$
\mathrm{N}_{\mathrm{cr}} ? 2.3 ? ? \mathrm{E} 1 ? \frac{7}{5} \sqrt[2]{\mathrm{n}_{\mathrm{h}}}
$$

For soils with linearly varying stiffness with depth and fixed top the buckling load is [6]:

$$
\mathrm{N}_{\mathrm{cr}} ? 4.2 ? ? \mathrm{E} ? ? \frac{7}{5} \cdot \sqrt[5]{\mathrm{n}_{\mathrm{h}}}
$$


If the soil stiffness varies in a more complicated way equivalent soil stiffness is calculated and the formulas above can be used. The plastic capacity of the pile is for hinged pile top [6]

$$
N_{p} ? \frac{2 ? M_{p}^{\prime}}{?}
$$

and for fixed pile top [5]

$$
N_{p} ? \frac{4 ? M_{p}^{\prime}}{?}
$$

When the buckling and plastic capacity of the pile have been calculated the normal force $\mathrm{N}$ horizontal displacement ? ${ }_{\mathrm{D}}$ and the rotation ? ?are?aken from the global analysis. The horizontal displacement of the pile top can be calculated as ? $\mathrm{D}+$ ? 2 where $e$ is the distance between the gravity centre of the composite section and the pile top.

\section{5) Conclusions}

The concept of bridges with integral abutments has several advantages such as minimised maintenance costs and the removal of joints and bearings at end supports of a bridge. The concept has been proved to be competitive in the USA, and is believed to be so in most countries, if only given the chance by contractors and the authorities. In Sweden the concept can save much effort, as no work has to be carried out under the water level. Laboratory tests as well as computer simulations indicate that the decrease in load capacity due to rotations and translations of the pile top should be no problem. A full scale in situ test of such a bridge, with respects to the stresses in the piles, should be worth carrying out, to verify the tests and simulations mentioned above.

\section{6) References}

[1] Greimann L F, Abendroth R E, Johnson D E and Ebner P B, Pile Design and Tests for Integral Abutment Bridges- Final Report, (1987), Iowa DOT Project HR-273, , Department of Civil Engineering Engineering Research Institute, Iowa State University

[2] GangaRao H, Thippeswamy H, Dickson B, Franco J, Survey and Design of Integral Abutment Bridges- Workshop on Integral Abutment Bridges 13-15, 1996 Pittsburg ,Pennsylvania Alampalli, Sreenivas and Yannotti P Arthur,- In Service Performance of Integral Bridges and Jointless Decks-Transportation Research Record 1624-pp. 1-7

[3] Theory of Elastic Stability, Timoshenko S.P., McGraw-Hill

[4] Pétursson Hans, Bridges with integral abutments, Licentiate thesis / 2000:32 (2000), Lulea University of Technology, Dept. of Steel Structures

[5] Granholm H, On the Elastic of Piles Surrounded by a Suporting Medium, Centraltryckeriet Stockholm, 1929

[6] Greimann L F and Wolde-Tinsae A M, Design Model For Piles In Jointless Bridges(1988), Journal of Structural Engineering, Vol. 114, No 6, pp 1354-1371, ISSN 0733-9445/88/00061354. 